\title{
Função de resposta da melancia aos níveis de água e adubação nitrogenada, no Vale do Curu, $\mathrm{CE}^{1}$
}

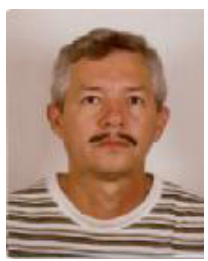

José I. Soares ${ }^{2}$, Raimundo N. T. Costa ${ }^{3}$, Luiz A. C. da Silva ${ }^{4}$ \& Rubens S. Gondim ${ }^{5}$

\footnotetext{
1 Parte da Dissertação de Mestrado apresentada pelo primeiro autor à UFC

2 R. Domingos Calazans 115, CEP 63.041-130, Juazeiro do Norte, CE. Fone: (88) 571-6315. E-mail: ivo soares@bol.com.br (Foto)

${ }^{3}$ DENA/CCA/UFC. Campus do Pici, Bloco 804, CEP 60455-760, Fortaleza, CE. Fone: (85) 288-9764. E-mail: rntcosta@ufc.br

4 DEA/CCA/UFC. Campus do Pici. Fone: (85) 288-9716

${ }^{5}$ Banco do Nordeste S.A. Fortaleza, CE. Fone: (85)299-3273. E-mail: sansol@banconordeste.gov.br
}

Protocolo $150-31 / 10 / 2001$

\begin{abstract}
Resumo: Estudar as relações entre lâminas de água e adubação nitrogenada e o rendimento da cultura da melancia, estabelecendo uma função de produção visando à otimização econômica do uso da água e da adubação nitrogenada a partir de uma estrutura de preços, foi o principal objetivo deste trabalho. $O$ delineamento experimental foi em blocos ao acaso com parcelas subdivididas e com quatro repetições, cujos tratamentos se constituíram pela combinação de cinco lâminas de irrigação $(312,1,288,5,252,6,205,2$ e $142,5 \mathrm{~mm})$ e quatro níveis de adubação nitrogenada $\left(0,75,150\right.$ e $\left.300 \mathrm{~kg} \mathrm{ha}^{-1}\right)$. Utilizou-se a cultura da melancia, variedade Crimson Sweet e as irrigações, controladas por tensiômetros instalados a 0,15 m de profundidade, indicando o momento de irrigar, quando o potencial mátrico atingir - $30 \mathrm{kPa}$. A produtividade máxima de $64.908,9 \mathrm{~kg} \mathrm{ha}^{-1}$ foi obtida com aplicação de uma lâmina de água de $227,3 \mathrm{~mm}$ e dose de $229,8 \mathrm{~kg} \mathrm{ha}^{-1}$ de nitrogênio. Constatou-se não ser vantajosa, do ponto de vista econômico, a substituição do fator lâmina de água pelo fator dose de nitrogênio. Quanto à eficiência ótima econômica do uso de água, foi estimada em $27,2 \mathrm{~kg} \mathrm{~m}^{-3}$ ou $272 \mathrm{~kg} \mathrm{ha}^{-1} \mathrm{~mm}^{-1}$, correspondente a uma adubação de $242,7 \mathrm{~kg} \mathrm{ha}^{-1}$.
\end{abstract}

Palavras-chave: Citrullus lanatus Thumb. Mansf., função de produção, irrigação

\section{Production functions for the yield of watermelon for different levels of irrigation and nitrogen fertilization in the Curu Valley, CE - Brazil}

\begin{abstract}
The objective of this research was to study the effect of different levels of irrigation and nitrogen fertilization applied to watermelon crop and to establish a production function aimed at economic optimization of the yield based on the costs of water and fertilizer. The experimental design consisted of randomized blocks with split plots combining five irrigation water levels $(312.1,288.5,252.6,205.2$ and $142.5 \mathrm{~mm}$ ) and four levels of fertilization (0, 75, 150 and $300 \mathrm{~kg} \mathrm{ha}^{-1}$ ) with four replications. The watermelon cultivar Crimson Sweet was used and the irrigations were monitored by tensiometers installed at $0.15 \mathrm{~m}$ of depth. The irrigation was applied when the soil matric potential reached $-30 \mathrm{kPa}$. The maximum productivity of $64,908.9 \mathrm{~kg} \mathrm{ha}^{-1}$ was obtained by the treatment that received $227.3 \mathrm{~mm}$ of water and $229.8 \mathrm{~kg} \mathrm{ha}^{-1}$ of nitrogen. The substitution of water for nitrogen was found to be not advantageous from the economic point of view. The optimum economic water use was estimated to be $27.2 \mathrm{~kg} \mathrm{~m}^{-3}$ or $272 \mathrm{~kg} \mathrm{ha}^{-1} \mathrm{~mm}^{-1}$, corresponding to $242.7 \mathrm{~kg} \mathrm{ha}^{-1}$ of nitrogen.
\end{abstract}

Key words: Citrullus lanatus Thumb. Mansf., production function, irrigation

\section{INTRODUÇÃO}

Apenas 1\% da água existente na Terra é doce e se encontra armazenada em rios, lagos e aqǘf́eros subterrâneos, mas distribuída de forma desigual. O Brasil com $8 \%$ desse manancial, é o país mais rico em água doce do mundo, porém a distribuição em toda a sua extensão territorial é bastante irregular, pois $80 \%$ ocorrem na bacia Amazônica, onde residem somente 5\% de sua população (Assis, 1998).

A adequação dos recursos hídricos à disponibilidade dos solos irrigáveis é seguramente mais pessimista no semi-árido do Nordeste brasileiro, região que, por suas características climáticas, principalmente a intensa insolação anual, é detentora de grande potencial para exploração de olerícolas e de 
fruticultura tropical irrigada. Com base nesta perspectiva, a cultura da melancia (Citrullus lanatus Thumb. Mansf.) pela capacidade de adaptação às condições climáticas e pelo elevado rendimento econômico, apresenta-se como uma das opções promissoras para o Nordeste brasileiro.

A melancia é bastante explorada em muitos países do mundo, como a Índia, Irã, Itália e os Estados Unidos. No Brasil, destacam-se como regiões produtoras o Sudeste, o CentroOeste e o Nordeste, na microrregião do Médio São Francisco, principalmente nos municípios de Petrolina e Juazeiro (Soares,1978). Com o fenômeno natural da seca em zonas áridas e semi-áridas, a utilização da irrigação é uma das poucas, quando não a única, para a produção agropecuária sustentável (FAO, 1993); o uso racional das águas poderá propiciar expansão da área irrigada, em função da sua maior disponibilidade.

A melancia tem sua produção comprometida quando o déficit hídrico ocorre no período da frutificação até o início da maturação; no período da maturação até a colheita, a exigência hídrica é bem menor, enquanto o excesso de água ocasiona rachadura nos frutos e presença de frutos insípidos e podridões (Casali et al., 1982).

A produtividade das culturas pode ser influenciada por diversos fatores, entre os quais o modo de aplicação de fertilizantes e a dosagem utilizada; além disso, a intensificação dos cultivos e o aspecto econômico requerem maior eficiência e controle nas aplicações de fertilizantes e água (Shani, 1981). Dentre os elementos que influenciam o desenvolvimento das plantas, o nitrogênio é de vital importância e, embora seja o mais abundante na natureza, representando cerca de $78 \%$ da composição do ar atmosférico (na forma gasosa não é disponível para a maioria das plantas) é o elemento que limita a produção das culturas (Neves, 1981).

A produção agrícola tem, como fatores complementares na rentabilidade econômica, a água e os nutrientes, e o uso eficiente desses recursos constitui fator preponderante para o êxito da agricultura. Um manejo eficiente da irrigação requer informações relacionadas às necessidades de água das culturas e da função de produção das culturas à água. O uso das funções de resposta permite encontrar-se soluções úteis na otimização do uso da água e dos fertilizantes, obtendo-se o máximo do produto com determinado custo de produção.

O conhecimento da função de resposta das culturas à água permite ao administrador melhor utilizar o recurso água, aumentando assim a eficiência econômica da empresa agrícola, pela flexibilidade da aplicação da lâmina de irrigação.

A pesquisa teve, como objetivo, estudar os efeitos das lâminas totais de água, dos níveis de adubação nitrogenada e da interação desses fatores sobre o rendimento da cultura da melancia, utilizando-se o sistema de irrigação por sulco.

\section{MATERIAL E MÉTODOS}

O experimento foi conduzido no período de setembro a dezembro de 1998, na área irrigada da Fazenda Experimental do Vale do Curu, Pentecoste, CE, em solo de textura franco-siltosa, clima do tipo Aw', ou seja, quente e úmido, com chuvas máximas no outono. A precipitação média anual é de $806,5 \mathrm{~mm}$ com distribuição irregular e umidade relativa média do ar de $73,8 \%$. Os dados físico-hídricos do solo são apresentados na Tabela 1.

A água utilizada no experimento procede do Açude General Sampaio, a qual, de acordo com a classificação de qualidade da água para irrigação indicada por Richards (1954) possui alto risco de salinidade $\left(\mathrm{C}_{3}\right)$ e não oferece perigo de sodificação $\left(\mathrm{S}_{1}\right)$.

O preparo do solo constou de aração, gradagem, aplainamento e sulcamento, com espaçamento entre sulcos de 1,60 m. Estabeleceu-se a cultura da melancia, variedade Crinson Sweet, no espaçamento $1,60 \times 1,00 \mathrm{~m}$. O delineamento experimental foi em blocos completos casualizados, com parcelas subdivididas e quadro repetições. As parcelas eram constituídas pelos tratamentos lâminas de água, e as subparcelas pelos tratamentos dosagens de nitrogênio, tendo cada parcela comprimento de $25,0 \mathrm{~m}$ e cada subparcela comprimento de 6,0 $\mathrm{m}$ com quatro fileiras de plantas na área útil. Os tratamentos consistiram da combinação de cinco lâminas de água: $(312,1$, $288,5,252,6,205,2$ e $142,5 \mathrm{~mm}$ ) e quatro níveis de nitrogênio $\left(0,75,150,300 \mathrm{~kg} \mathrm{ha}^{-1}\right)$, cuja fonte utilizada foi uréia.

O sistema de aplicação de água utilizado foi por sulcos retos e abertos em declive, com $120 \mathrm{~m}$ de comprimento e espaçados $1,60 \mathrm{~m}$. Para que todos os sifões trabalhassem com a mesma carga hidráulica, instalou-se um piquete no início de cada sulco, com a finalidade de proporcionar uma carga em todos os sulcos, igual a $0,62 \mathrm{~m}$ e, portanto, uma vazão de $0,72 \mathrm{~L} \mathrm{~s}^{-1}$, em sifões corrugados com diâmetro de $0,025 \mathrm{~m} \mathrm{e} \mathrm{4,0}$ $\mathrm{m}$ de comprimento. Adaptou-se, também, uma comporta, que era colocada na secção do canal, com o propósito de conservar o nível de água constante durante as irrigações.

No controle da irrigação utilizou-se tensiometria, procedendo-se às irrigações sempre que o potencial mátrico do solo atingia $-30 \mathrm{kPa}$, em tensiômetros instalados a $0,15 \mathrm{~m}$ de profundidade. No cálculo das lâminas requeridas utilizaram-se também dos dados de tensiômetros instalados na profundidade de $0,45 \mathrm{~m}$. Em cada um dos quatro blocos instalou-se um conjunto de tensiômetros, nas profundidades de 0,15 e $0,45 \mathrm{~m}$, distanciados de $0,10 \mathrm{~m}$ e localizados no centro da segunda parcela, ou seja, a 37,5 m da cabeceira do sulco de irrigação. Os tensiômetros foram instalados a uma distância de $0,05 \mathrm{~m}$ lateralmente à planta e a $0,10 \mathrm{~m}$ da borda do sulco de irrigação.

O tempo de oportunidade de infiltração no ponto médio de cada parcela experimental era calculado com base na equação de infiltração obtida através do método dos dois pontos, em cada evento de irrigação. Com a finalidade de se obter parcelas

Tabela 1. Dados físico-hídricos* do solo da área do experimento

\begin{tabular}{|c|c|c|c|c|c|c|c|c|c|c|c|c|}
\hline \multirow{2}{*}{ Prof. (m) } & \multicolumn{6}{|c|}{ Composição Granulométrica $-\mathrm{g} \mathrm{kg}^{-1}$} & \multirow{2}{*}{ GF } & \multicolumn{2}{|c|}{ Densidade $\left(\mathrm{kg} \mathrm{dm}^{-3}\right)$} & \multicolumn{2}{|c|}{ Umidade $\left(\mathrm{g} \mathrm{kg}^{-1}\right)$} & \multirow{2}{*}{$\begin{array}{l}\text { Água Útil } \\
\mathrm{g} \mathrm{kg}^{-1}\end{array}$} \\
\hline & $\mathrm{AG}$ & $\mathrm{AF}$ & $\mathrm{S}$ & A & AN & $\mathrm{CT}$ & & Solo & Partículas & $1 / 3 \mathrm{~atm}$ & $15 \mathrm{~atm}$ & \\
\hline $\mathrm{I}(0-0,30)$ & 280 & 150 & 400 & 170 & 130 & Franco & 23 & 1,36 & 2,57 & 188,1 & 89,8 & 98,3 \\
\hline II $(0,30-0,60)$ & 90 & 60 & 570 & 280 & 90 & Franco siltoso & 68 & 1,44 & 2,57 & 285,6 & 159,5 & 126,1 \\
\hline
\end{tabular}

AG - Areia grossa; AF - Areia fina; S - Silte; A - Argila; AN - Argila natural; CT - Classe textural, GF - Grau de floculação 
com excesso e parcelas com déficit de umidade, a aplicação de água restringiu-se apenas à fase de avanço, cuja equação de ajuste era obtida a cada evento de irrigação, em sulcos com 125,0 m de comprimento, conforme preconizado por Scaloppi (1983).

O custo da irrigação (CI) foi composto pelo custo da tarifa d'água obtida junto ao Departamento Nacional de Obras Contra a Seca (DNOCS), correspondendo a R\$ 0,0114 m³ (11/98) acrescido aos custos de aplicação, amortização e manutenção conforme a seguinte equação:

$$
\mathrm{CI}=\frac{\mathrm{C}_{\mathrm{ap}}+\mathrm{C}_{\mathrm{am}}+\mathrm{C}_{\mathrm{man}}}{\text { Lreq. }^{\text {ciclo }}}+\mathrm{C}_{\text {tar. }}
$$

em que:

CI - custo da irrigação, $\mathrm{R} \$ \mathrm{~mm}^{-1}$ aplicado

$\mathrm{C}_{\text {ap. }}$ - custo de aplicação, $\mathrm{R} \$$

$\mathrm{C}_{\mathrm{am}}^{\mathrm{ap}}$ - custo da amortização, $\mathrm{R} \$$

$\mathrm{C}_{\text {man }}^{\mathrm{am}}$ - custo de manutenção, $\mathrm{R} \$$

$\mathrm{C}_{\text {tar. }}$ - custo da tarifa d'água, $\mathrm{R} \$ \mathrm{~mm}^{-1}$

$\mathrm{L}_{\text {req }}$ - lâmina de irrigação requerida no ciclo da cultura, $\mathrm{mm}$

Na estimativa do custo de aplicação considerou-se o custo com mão-de-obra relativa à aplicação de água durante o ciclo da cultura e a lâmina de irrigação requerida ou necessária durante o ciclo, conforme Oliveira Jr. (1998). No custo de amortização considerou-se o valor estabelecido pelo DNOCS $\left(\mathrm{K}_{1}\right)$ no valor de R\$111,06, para fins de amortização da infra-estrutura de uso comum. No custo de manutenção considerou-se o custo equivalente a $3 \%$ do custo de implantação do sistema (Leitch, 1983, citado por Duarte 1997).

$\mathrm{Na}$ definição da função de produção que estima o rendimento em função das lâminas de água (L) e doses de nitrogênio $(\mathrm{N})$ testaram-se dez modelos estatísticos que se têm mostrado adequados em estudos anteriores no Brasil e no mundo, conforme Aguiar (1989). A escolha do modelo que melhor representasse a função $\mathrm{y}=\mathrm{y}(\mathrm{L}, \mathrm{N})$, baseou-se na análise do coeficiente de determinação, coeficiente de determinação ajustado, teste $\mathrm{F}$ para análise de variância, teste $\mathrm{t}$ para os coeficientes das variáveis e coerência dos sinais das variáveis no modelo.

O produto físico marginal corresponde ao produto adicional obtido ao se usar uma unidade adicional do fator. Os valores dos produtos físicos marginais foram obtidos da equação da superfície de resposta, em função das lâminas totais de água e das doses de nitrogênio. A taxa marginal de substituição do fator lâmina de água pelo fator dosagem de nitrogênio corresponde à quantidade do fator água que se dispõe a abandonar para empregar uma unidade a mais do fator nitrogênio, mantendo-se no mesmo nível de produção, sendo calculada pela relação entre o produto físico marginal do fator água e o produto físico marginal do fator dosagem de nitrogênio.

As curvas de isoproduto correspondem às combinações possíveis dos fatores água e dosagem de nitrogênio, suficientes para produzir um rendimento da cultura. A região de produção racional obtida da análise das curvas de isoproduto, correspondem às partes das curvas de isoproduto que se encontram entre as linhas de fronteiras, com produto físico marginal nulo. A eficiência de uso da água foi calculada pela relação entre o rendimento da cultura e a lâmina total de água infiltrada durante o ciclo da cultura.

\section{RESULTADOS E DISCUSSÃO}

\section{Superfície de resposta}

Dentre os modelos testados, o que melhor se ajustou às evidências obtidas na pesquisa, foi o modelo quadrático, segundo a equação:

$$
\mathrm{Y}=467,6946 \mathrm{~L}+102,2395 \mathrm{~N}-1,0286 \mathrm{~L}^{2}-0,2225 \mathrm{~N}^{2}
$$

sendo:

$\mathrm{Y}$ - rendimento da melancia, $\mathrm{kg} \mathrm{ha}^{-1}$

L - lâmina total de água infiltrada, $\mathrm{mm}$

$\mathrm{N}$ - dose de nitrogênio, $\mathrm{kg} \mathrm{ha}^{-1}$

O coeficiente de determinação $\left(\mathrm{R}^{2}\right)$ igual a 0,9917 indica um ótimo ajustamento do modelo. Os resultados do teste $t$ demonstraram efeitos altamente significativos para os parâmetros das variáveis I e $\mathrm{I}^{2}$ (Probabilidade $\left.>|\mathrm{T}|=0,0001\right) \mathrm{e}$ significativo para a variável N (Probabilidade $>|\mathrm{T}|=0,0259$ ). Embora o parâmetro da variável $\mathrm{N}^{2}$ (Probabilidade $\left.>|\mathrm{T}|=0,1036\right)$ não tenha evidenciado efeito significativo a nível de $5 \%$, o erro ao se incorporar tal parâmetro na equação, encontra-se dentro dos padrões aceitáveis.

A Figura 1 representa graficamente a função de produção, cujo rendimento máximo estimado de $64.908,8 \mathrm{~kg} \mathrm{ha}^{-1}$, foi obtido com lâmina total de água de $227,7 \mathrm{~mm}$ e dose de $229,8 \mathrm{~kg} \mathrm{ha}^{-1} \mathrm{de}$ nitrogênio. Evidencia-se um efeito altamente significativo do fator lâminas totais de água sobre o rendimento da cultura da melancia indicando, desta forma, que o fator lâminas de água foi mais limitante no rendimento da cultura que o fator doses de nitrogênio. Tal análise pode ser observada face aos gradientes de declive das linhas, que compõem a superfície de resposta, serem mais acentuados para o fator lâminas totais de água que para o fator doses de nitrogênio.

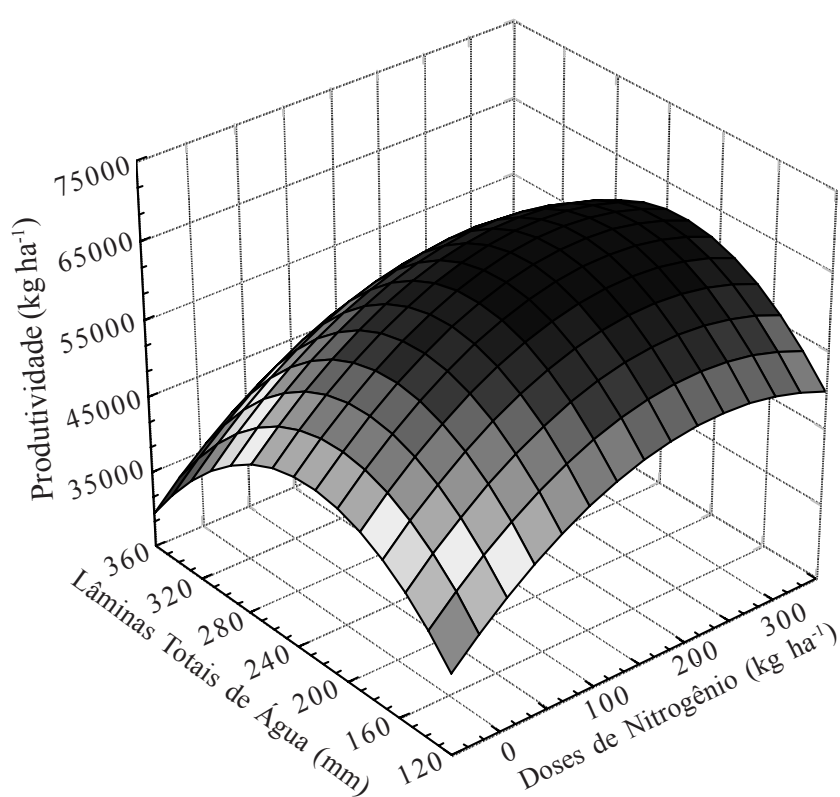

Figura 1. Rendimento da melancia aos níveis de água e doses de nitrogênio 


\section{Produto físico marginal}

Os valores dos produtos físicos marginais de lâminas totais de água dentro das doses de nitrogênio e dos produtos físicos marginais das doses de nitrogênio dentro das lâminas totais de água, não apresentaram variação, como decorrência do fato da equação melhor ajustada não apresentar interação entre os fatores (Tabela 2).

Tabela 2. Produtos físicos marginais da água, para diferentes lâminas totais de água (valor superior) e do nitrogênio para diferentes doses de nitrogênio (valor inferior)

\begin{tabular}{crrrr}
\hline \multirow{2}{*}{$\begin{array}{c}\text { Lâmina Total } \\
\text { de Água }(\mathrm{mm})\end{array}$} & \multicolumn{4}{c}{ Dose de Nitrogênio $\left(\mathrm{kg} \mathrm{ha}^{-1}\right)$} \\
\cline { 2 - 5 } 142,5 & 174,54 & 174,54 & 174,54 & \multicolumn{1}{c}{300} \\
\hline \multirow{2}{*}{205,2} & 102,24 & 68,86 & 35,49 & $-31,26$ \\
& 45,54 & 45,54 & 45,54 & 45,54 \\
252,6 & 102,24 & 68,86 & 35,49 & $-31,26$ \\
& $-51,91$ & $-51,91$ & $-51,91$ & $-51,91$ \\
288,4 & 102,24 & 68,86 & 35,49 & $-31,26$ \\
& $-125,70$ & $-125,70$ & $-125,70$ & $-125,70$ \\
312,1 & 102,24 & 68,86 & 35,49 & $-31,26$ \\
& $-174,32$ & $-174,32$ & $-174,32$ & $-174,32$ \\
& 102,24 & 68,86 & 35,49 & $-31,26$ \\
\hline
\end{tabular}

Em relação às lâminas totais de água, o produto físico marginal diminui com o aumento da mesma, e no intervalo de 205,2 a 252,6 mm, encontra-se o ponto a partir do qual é antieconômico o aumento das lâminas totais de água; este ponto, por outro lado, corresponde a uma lâmina total de água de 227,3 mm, cujo produto físico marginal é igual a zero e, portanto, proporciona a maior produtividade. Da mesma forma para doses de nitrogênio, o produto físico marginal diminui com o aumento das doses, em um ponto a partir do qual é antieconômico o aumento nas doses de nitrogênio encontrando-se no intervalo de 150 a $300 \mathrm{~kg} \mathrm{ha}^{-1}$. Referido ponto corresponde a uma dose de $229,7 \mathrm{~kg} \mathrm{ha}^{-1}$, cujo produto físico marginal é igual a zero proporcionando, assim, a maior produtividade.

\section{Curvas de isoproduto}

As isolinhas de produção (Fig. 2) traçadas com eqüidistância vertical de $10.000 \mathrm{~kg} \mathrm{ha}^{-1}$, mostram decréscimo gradual nas declividades, entre curvas consecutivas, com aumento no rendimento. Explica-se tal fato, tendo em vista os incrementos

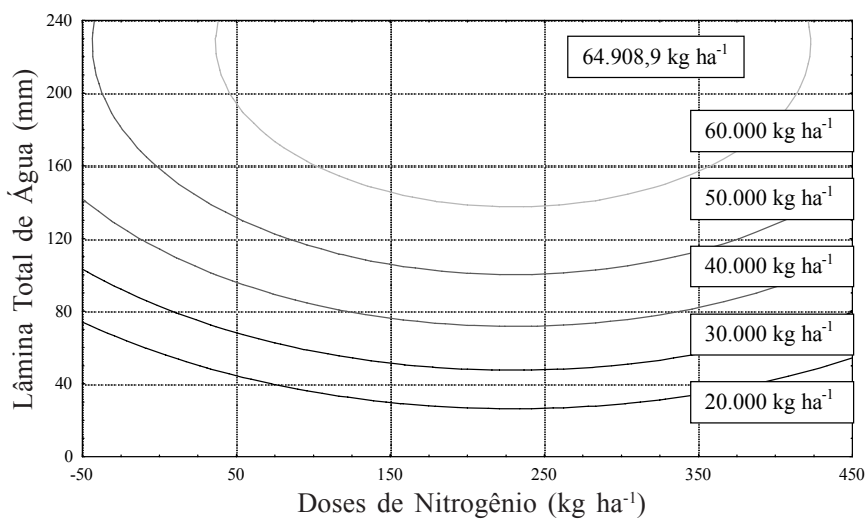

Figura 2. Isolinhas de produção da melancia em função de lâmina de água e doses de nitrogênio

de rendimento cada vez menores à medida que se aumenta o uso dos fatores de produção.

Taxa marginal de substituição e região de produção racional

As taxas marginais de substituição de lâminas de água por doses de nitrogênio para níveis prefixados de rendimentos da melancia são apresentadas na Tabela 3. Quanto mais água e menos nitrogênio for usado para obtenção do mesmo nível de produção de melancia, mais difícil se torna substituir adubo por água. A declividade em cada ponto da curva de produto constante corresponde à taxa marginal de substituição de água por adubo. Observa-se que os valores absolutos das taxas marginais de substituição de água por adubo diminuem à medida que se aumenta a dose de nitrogênio e se reduz a lâmina de água, portanto com a substituição do fator água pelo fator nitrogênio.

Considerando-se o rendimento da melancia de $50.000 \mathrm{~kg} \mathrm{ha}^{-1}$, observa-se que, com um incremento nas doses de nitrogênio até $240 \mathrm{~kg} \mathrm{ha}^{-1}$, a taxa marginal de substituição é negativa, indicando que os dois fatores de produção se comportam como substitutos. A partir desse ponto, para que seja mantido o rendimento de $50.000 \mathrm{~kg} \mathrm{ha}^{-1}$, à medida que são usadas maiores quantidades de nitrogênio, são necessárias, também, maiores quantidades de água, comportando-se os fatores como complementares, tornando-se antieconômico.

Na obtenção de um rendimento de $50.000 \mathrm{~kg} \mathrm{ha}^{-1}$, a lâmina mínima de água necessária será $107 \mathrm{~mm}$, coincidindo com o ponto $\mathrm{D}$ em que a dose de nitrogênio utilizada foi de $229,6 \mathrm{~kg} \mathrm{ha}^{-1}$, sendo a inclinação da isoquanta nula, conforme Figura 3.

Tabela 3. Taxas marginais de substituição de água por nitrogênio $\left(\mathrm{TMS}_{\mathrm{L} / \mathrm{N}}\right)$ para níveis prefixados de rendimentos da melancia

\begin{tabular}{|c|c|c|c|c|c|c|c|c|c|c|}
\hline \multirow[b]{2}{*}{$\begin{array}{c}\mathrm{N} \\
\left(\mathrm{kg} \mathrm{ha}^{-1}\right)\end{array}$} & \multicolumn{2}{|c|}{$\mathrm{y}=20.000 \mathrm{~kg} \mathrm{ha}^{-1}$} & \multicolumn{2}{|c|}{$\mathrm{y}=30.000 \mathrm{~kg} \mathrm{ha}^{-1}$} & \multicolumn{2}{|c|}{$\mathrm{y}=40.000 \mathrm{~kg} \mathrm{ha}^{-1}$} & \multicolumn{2}{|c|}{$\mathrm{y}=50.000 \mathrm{~kg} \mathrm{ha}^{-1}$} & \multicolumn{2}{|c|}{$\mathrm{y}=60.000 \mathrm{~kg} \mathrm{ha}^{-1}$} \\
\hline & $\begin{array}{c}\mathrm{L} \\
(\mathrm{mm})\end{array}$ & TMS & $\begin{array}{c}\mathrm{L} \\
(\mathrm{mm})\end{array}$ & TMS & $\begin{array}{c}\mathrm{L} \\
(\mathrm{mm})\end{array}$ & TMS & $\begin{array}{c}\mathrm{L} \\
(\mathrm{mm})\end{array}$ & TMS & $\begin{array}{c}\mathrm{L} \\
(\mathrm{mm})\end{array}$ & TMS \\
\hline 0 & 47,78 & $-0,27$ & 77,28 & $-0,33$ & 114,22 & $-0,44$ & 171,88 & $-0,90$ & - & - \\
\hline 40 & 37,95 & $-0,21$ & 65,64 & $-0,25$ & 99,17 & $-0,32$ & 145,46 & $-0,50$ & - & - \\
\hline 80 & 30,34 & $-0,16$ & 56,80 & $-0,19$ & 88,19 & $-0,23$ & 129,14 & $-0,33$ & - & - \\
\hline 120 & 24,73 & $-0,12$ & 50,33 & $-0,13$ & 80,34 & $-0,16$ & 118,31 & $-0,22$ & 80,80 & $-0,51$ \\
\hline 160 & 20,93 & $-0,07$ & 46,00 & $-0,08$ & 75,15 & $-0,10$ & 111,41 & $-0,13$ & 66,35 & $-0,25$ \\
\hline 200 & 18,85 & $-0,03$ & 43,64 & $-0,04$ & 72,35 & $-0,04$ & 107,75 & $-0,05$ & 59,66 & $-0,10$ \\
\hline 240 & 18,45 & $-0,01$ & 43,18 & $-0,01$ & 71,80 & $-0,01$ & 107,05 & $-0,02$ & 58,43 & $-0,03$ \\
\hline 280 & 19,71 & $+0,05$ & 44,61 & $+0,05$ & 73,49 & $+0,07$ & 109,24 & $+0,09$ & 162,33 & $+0,17$ \\
\hline 320 & 22,65 & $+0,10$ & 47,96 & $+0,10$ & 77,50 & $+0,13$ & 114,51 & $+0,17$ & 172,48 & $+0,36$ \\
\hline 360 & 27,37 & $+0,14$ & 53,37 & $+0,16$ & 84,00 & $+0,20$ & 123,30 & $+0,27$ & 194,14 & $+0,84$ \\
\hline 400 & 33,98 & $+0,19$ & 60,00 & $+0,22$ & 93,38 & $+0,27$ & 136,65 & $+0,41$ & - & - \\
\hline
\end{tabular}




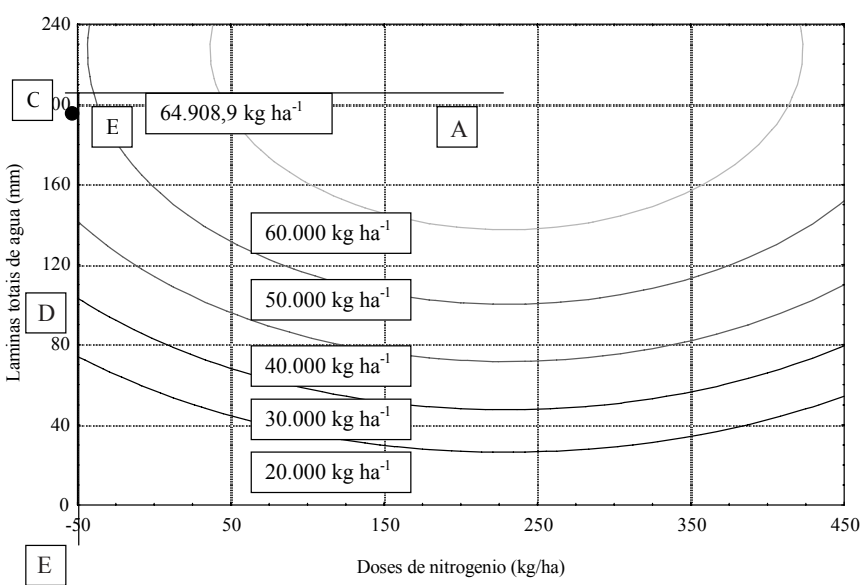

Figura 3. Região de produção racional

A linha $\mathrm{AB}$ que liga os pontos em que as isoquantas têm inclinação nula, é chamada linha de fronteira (Leftwich, 1976), isto é, todas as combinações de água e adubo situadas à sua direita são irracionais e determinam as menores lâminas de água que devem ser usadas para obtenção de determinado rendimento.

Considerando-se, ainda, o nível de produtividade de 50.000 $\mathrm{kg} \mathrm{ha-1}$ com relação ao ponto $\mathrm{E}$, observa-se não ser mais necessário a utilização de nitrogênio para uma aplicação de água correspondente a $227,3 \mathrm{~mm}$. Neste ponto, a inclinação da isoquanta é infinita, mostrando que o nitrogênio foi substituído pela água até onde foi possível.

AC é uma linha de fronteira que liga os pontos em que as isoqüantas têm inclinação infinita, pois qualquer combinação de água e de nitrogênio situada à sua esquerda, é irracional. Também determina as menores quantidades de nitrogênio que devem ser utilizadas para obtenção de um certo nível de rendimento.

Frizzone (1986) afirma ser vantajoso substituir água por nitrogênio, sempre que a quantidade do fator acrescentado (N) vezes o seu preço, for menor que a quantidade de recurso substituído (L) vezes o seu preço, significando que, sempre que o valor absoluto da taxa marginal de substituição entre os fatores for maior que a relação inversa entre os respectivos preços, é vantajoso substituir L por N.

Conforme se observa na Tabela 2, todos os valores das TMS $_{\mathrm{L} / \mathrm{N}}$, são inferiores ao valor da relação $\mathrm{P}_{\mathrm{N}} / \mathrm{P}_{\mathrm{L}}$, podendo-se concluir, desta forma, não ser vantajosa a substituição de $\mathrm{L}$ por $\mathrm{N}$ para as condições da pesquisa.

\section{Eficiência de uso da água}

Os valores médios para eficiência de uso da água (EUA) em função das lâminas totais de água e das doses de nitrogênio, são apresentados na Tabela 4, na qual se observou tendência de uso da água com maior eficiência, a medida em que se aumentava a dose de nitrogênio. Constatou-se, também, que nas parcelas que receberam maior nível de adubação nitrogenada $\left(300 \mathrm{~kg} \mathrm{ha}^{-1}\right)$ a eficiência de uso da água decresceu com o aumento da lâmina total de água.

O valor máximo para eficiência de uso da água, de $27,2 \mathrm{~kg} \mathrm{~m}^{-3}$ ou $272 \mathrm{~kg} \mathrm{ha}^{-1} \mathrm{~mm}^{-1}$, para uma dosagem de nitrogênio de $242,7 \mathrm{~kg} \mathrm{ha}^{-1}$, foi estimado com base no ajuste de uma função
Tabela 4. Valores médios da eficiência de uso da água $\left(\mathrm{kg} \mathrm{ha}^{-1}\right.$ $\mathrm{mm}^{-1}$ )

\begin{tabular}{cccccc}
\hline \multirow{2}{*}{$\begin{array}{c}\text { Lâm. Água } \\
(\mathrm{mm})\end{array}$} & 0 & 75 & 150 & 300 & Médias \\
\cline { 2 - 6 } & 132,3 & 156,8 & 174,5 & 158,6 & 155,6 \\
312,1 & 184,9 & 194,9 & 240,7 & 238,5 & 214,7 \\
288,4 & 225,2 & 233,1 & 262,6 & 224,3 & 236,3 \\
252,6 & 271,9 & 259,6 & 293,6 & 279,4 & 276,1 \\
205,2 & 299,0 & 349,8 & 388,9 & 460,2 & 374,5 \\
142,5 & $222,6 \mathrm{~b}$ & $238,8 \mathrm{ab}$ & $272,1 \mathrm{a}$ & $272,2 \mathrm{a}$ & \\
Médias & & & & &
\end{tabular}

do tipo polinomial de segundo grau, cujo coeficiente de determinação $\left(\mathrm{R}^{2}\right)$ foi de 0,93 , e significativa a nível de $5 \%$ probabilidade.

\section{CONCLUSÕES}

1. A estimativa de rendimento máximo da melancia, de $64.908,9 \mathrm{~kg} \mathrm{ha}^{-1}$, com base na função de produção da cultura, dos níveis de água e nitrogênio, foi obtida com uma lâmina total de água de 227,3 mm e uma dosagem de $229,8 \mathrm{~kg} \mathrm{ha}^{-1} \mathrm{de}$ nitrogênio.

2. O produto físico marginal diminuiu com o aumento nos níveis de água obtendo-se, no intervalo entre 205,2 e 252,6 mm, o ponto de valor zero, de forma semelhante com o fator dosagens de nitrogênio, em que referido ponto se encontra no intervalo entre 150 e $300 \mathrm{~kg} \mathrm{ha}^{-1}$.

3. Os fatores água e adubação nitrogenada se comportaram como substitutos até a dosagem de $240 \mathrm{~kg} \mathrm{ha}^{-1}$ de nitrogênio, porém acima desta dosagem eles se comportaram como complementares.

4. A substituição do fator lâminas de água pelo fator dosagem de nitrogênio, não apresentou vantagem econômica.

5. A eficiência ótima econômica do uso de água no valor de $27,2 \mathrm{~kg} \mathrm{~m}^{-3}$ ou $272 \mathrm{~kg} \mathrm{ha}^{-1} \mathrm{~mm}^{-1}$, corresponde a uma adubação nitrogenada de $242,7 \mathrm{~kg} \mathrm{ha}^{-1}$.

\section{LITERATURA CITADA}

Aguiar, J.V. Determinação do consumo de água e da função de produção do caupi irrigado no Município de Bragança, Pará, Fortaleza: UFC, 1989. 106p. Dissertação Mestrado

Assis, J.C. Água sob medida. Rio de Janeiro: Fundação Getúlio Vargas, v.18, n.3, p.63-66, 1998.

Casali, V.W.M.; Sonnenberg, P.E. \& Pedrosa, J.F. Melancia: Cultivares e métodos culturais. Informe Agropecuário, Belo Horizonte, v.8, n.85, p.29-32, 1982.

Duarte, S.N. Modelo para avaliação de desempenho de sistemas de drenagem subterrânea e cálculo de espaçamento de drenos. Viçosa: UFV, 1997. 143p. Tese Doutorado

FAO. Sustainable management of water resources for agricultural development. In: The world of agriculture. Hong Kong: FAO, 1993. p.110-112.

Frizzone, J.A. Funções de resposta do feijoeiro ao uso de nitrogênio e lâmina de irrigação. Piracicaba: ESALQ/USP, 1986. 133p. Tese Doutorado

Leftwich, P. H. O sistema de preços e a locação de recursos. São Paulo: Pioneira, 1976. 399p. 
Neves, M.C.P. Interdependência fisiológica entre os componentes do sistema simbiótico Rhizobium leguminosas. Revista Brasileira de Ciência do Solo, Campinas, v.5, p.79-82, 1981.

Oliveira Jr., N.M. Análise econômico-comparativa de planos de cultivo em solos sódico submetido a um manejo integrado de recuperação. Revista Brasileira de Engenharia Agrícola e Ambiental, Campina Grande, v.2, n.2, p.165-169, 1998.

Richards, L.A. Suelos salinos y sodicos. México: Ed. Cultura, 1954. 172p.
Scaloppi, E. J. Metodologia para determinação de função de produção da água. Irrigação e Tecnologia Moderna, Brasília, n.15, p.31-33, 1983.

Shani, M. La fertilización combinada com el riego. Tel Aviv: Ministério de Agricultura, Servicio de Extension, 1981. 36p.

Soares, J.M. Influência de métodos de irrigação, sistemas e fórmulas de adubação na cultura da melancia. In: Congresso Brasileiro de Olericultura, 18, 1978, Mossoró. Resumo... Petrolina: EMBRAPA-CPATSA, 1978. 7p. 